(c) American Dairy Science Association, 2003.

\title{
Effect of Incomplete Pedigrees on Estimates of Inbreeding and Inbreeding Depression for Days to First Service and Summit Milk Yield in Holsteins and Jerseys
}

\author{
B. G. Cassell, V. Adamec, ${ }^{1}$ and R. E. Pearson \\ Department of Dairy Science \\ Virginia Polytechnic Institute and State University \\ Blacksburg 24061-0315
}

\begin{abstract}
A method to measure completeness of pedigree information is applied to populations of Holstein (registered and grade) and Jersey (largely registered) cows. Inbreeding coefficients where missing ancestors make no contribution were compared to a method using average relationships for missing ancestors. Estimated inbreeding depression was from an animal model that simultaneously adjusted for breeding values. Inbreeding and its standard deviation increased with more information, from $0.04 \pm 0.84$ to $1.65 \pm 2.05$ and $2.06 \pm 2.22$ for grade Holsteins with $<31 \%, 31$ to $70 \%$, and 71 to $100 \%$ complete five-generation pedigrees. Inbreeding from the method of average relationships for missing ancestors was $2.75 \pm 1.06,3.10 \pm 2.21$, and $2.89 \pm 2.37$ for the same groups. Pedigrees of registered Holsteins and Jerseys were over $97 \%$ and over $89 \%$ complete, respectively. Inbreeding depression in days to first service and summit milk yield was estimated from both methods. Inbreeding depression for days to first service was not consistently significant for grade Holsteins and ranged from $-0.37 \mathrm{~d} / 1 \%$ increase in inbreeding (grade Holstein pedigrees $<31 \%$ complete) to $0.15 \mathrm{~d}$ for grade Holstein pedigrees $>70 \%$ complete. Estimates were similar for both methods. Inbreeding depression for registered Holsteins and Jerseys were positive (undesirable) but not significant for days to first service. Inbreeding depressed summit milk yield significantly in all groups by both methods. Summit milk yield declined by -0.12 to $-0.06 \mathrm{~kg} / \mathrm{d}$ per $1 \%$ increase in inbreeding in Holsteins and by $-0.08 \mathrm{~kg} / 1 \%$ increase in inbreeding in Jerseys. Pedigrees of grade animals are frequently incomplete and can yield misleading estimates of inbreeding depression. This problem is not overcome by inserting average relationships for missing ancestors in calculation of inbreeding coefficients.
\end{abstract}

Received March 13, 2003.

Accepted April 28, 2003.

Corresponding author: B. G. Cassell; e-mail: bcassell@vt.edu.

${ }^{1}$ Present location: University of Brno, Czech Republic.
(Key words: incomplete pedigree, inbreeding depression, milk yield, days to first service)

\begin{abstract}
Abbreviation key: ABTK = Animal Breeders Toolkit, AIPL = Animal Improvement Programs Laboratory, DTS = days to first service, $\mathbf{S M}=$ summit milk yield .
\end{abstract}

\section{INTRODUCTION}

Incomplete pedigree information reduces estimates of inbreeding (Lutaaya et al., 1999). Detection of inbreeding depression depends on accurate estimates of inbreeding. Smith et al. (1998) reported inbreeding depression for lifetime performance traits of Holsteins that were 2 to 2.5 times larger in registered cows than in grade cows. Inbreeding also affects genetic evaluations. Phenotypes from animals with partial pedigrees are critical to accurate genetic evaluations, but the utility of such phenotypes is restricted by unknown relationships to other animals in the population. Partial pedigree data is particularly damaging to animal models that simultaneously consider additive and nonadditive genetic variation (Miglior et al., 1995; Wiggans et al., 1995). VanRaden (1992) presented a method that substituted average genetic relationships for animals born in different years in place of the assumed relationship of zero between known and unknown animals that is used in classical procedures. Miglior and Burnside (1995) applied the procedure to Canadian Holsteins, and showed that missing or incorrect pedigrees caused underestimation of inbreeding coefficients. Wiggans et al. (1995) developed a method to apply VanRaden's procedure and reported that inclusion of inbreeding coefficients in the inverse of the relationship matrix resulted in a more accurate representation of relationships among animals than ignoring missing information.

The method of VanRaden (1992) will estimate inbreeding for animals with very limited pedigree information. Such estimates vary less for animals with the same birth year than would be expected of inbreeding coefficients calculated from complete and accurate pedigrees of the same animals. VanRaden's procedure pro- 
Table 1. Possible contributions of the sire of individual $X$ to the numerator of the inbreeding coefficient for $\mathrm{X}$ in a five-generation pedigree. ${ }^{1}$

\begin{tabular}{llllll}
\hline Ancestors & $\mathrm{n}$ & Contribution & Ancestors & $\mathrm{n}$ & Contribution \\
\hline S = SD & 1 & 0.5 & S = SSSSD & 4 & 0.0625 \\
S = SSD & 2 & 0.25 & S = SDSSD & 4 & 0.0625 \\
S = SDD & 2 & 0.25 & S = SSDSD & 4 & 0.0625 \\
S = SSSD & 3 & 0.125 & S = SDDSD & 4 & 0.0625 \\
S = SDSD & 3 & 0.125 & S = SSSDD & 4 & 0.0625 \\
S = SSDD & 3 & 0.125 & S = SDSDD & 4 & 0.0625 \\
S = SDDD & 3 & 0.125 & S = SSDDD & 4 & 0.0625 \\
& & & S = SDDDD & 4 & 0.0625 \\
\hline
\end{tabular}

\footnotetext{
${ }^{1}$ Based on the classical inbreeding formula: $\mathrm{F}_{(\mathrm{x})}=\Sigma(1 / 2)^{n+1}\left(1+\mathrm{F}_{(\mathrm{a})}\right)$. The sum of all possible contributions
} from the sire is 2.0 .

duces higher estimates of inbreeding than true values for animals whose parents were less related than average for their birth year and underestimates inbreeding when parents were more closely related than average. The magnitude of overestimates is limited by average relationship, but underestimates of inbreeding could be quite large for highly inbred animals with limited pedigree data. Thus, VanRaden's approximations may be inappropriate in studies of inbreeding depression. Our purpose in this study is to present a method to evaluate the amount of information in a pedigree for estimation of inbreeding coefficients. We also compare estimates of inbreeding depression for interval to first breeding and summit milk yield based on inbreeding adjusted and unadjusted for unknown ancestors in field data on Holstein and Jersey cows.

\section{MATERIALS AND METHODS}

\section{Evaluating Inbreeding with Partial Pedigrees}

Performance data on dairy cows are often collected under field conditions where pedigree information may not be complete. Wiggans et al. (1995) reported that $90 \%$ of Holstein cows born during 1990, all of which were required to have valid sire identifications, also had dam identification, but only $74 \%$ of maternal grandsire and $70 \%$ of maternal grand dam identifications were available. Missing pedigree information limits the utility of field data for studies of inbreeding depression, as inbreeding from such data tends to be underestimated. A single missing ancestor several generations back in a pedigree has little potential impact on inbreeding, but a missing ancestor closer in the pedigree could cause serious underestimation. At the extreme, if either the sire or the dam is missing, detection of common ancestors and estimation of increased homozygosity by classic computations is not possible.

We developed a method to calculate the percentage of information available for detection of inbreeding in each of the pedigrees used in this study. The calcula- tions are best viewed as a quantitative measure of our ability to declare an individual to be non-inbred based on pedigree information available. The method accounts for all possible combinations of missing ancestors in a five-generation pedigree. Extension of the procedure to more or fewer generations is straightforward. Figure 1 shows the abbreviations used in this explanation, and equation [1] provides the basis of our calculations.

Inbreeding in individual $\mathrm{X}$ can be estimated by the classical equation:

$$
\mathrm{F}_{(\mathrm{x})}=\left[\Sigma(1 / 2)^{n}\left(1+\mathrm{F}_{(\mathrm{a})}\right)\right] / 2 .
$$

$\mathrm{F}_{(\mathrm{x})}$ is the inbreeding coefficient of individual $\mathrm{x}, n$ is the number of Mendelian segregations separating parents of $\mathrm{X}$ through common ancestor $\mathrm{a}, \mathrm{F}_{(\mathrm{a})}$ is the inbreeding coefficient of that ancestor, and summation is across all independent paths through all common ancestors. This equation is sometimes expressed with the exponent $n+1$ and no division by 2 .

For $\mathrm{S}$ in Figure 1 to be a common ancestor to $\mathrm{S}$ and $\mathrm{D}$, he would need to appear as SD, SSD, SSSD, or any of the other males on the maternal side of the pedigree. If $\mathrm{S}$ and SD were the same individual, one Mendelian segregation would separate $\mathrm{S}$ from $\mathrm{D}$, and the relationship would contribute $(1 / 2)^{n}=(1 / 2)^{1}=0.5$ to the numerator of Equation 1. If SD were missing, we could not declare $\mathrm{S}=\mathrm{SD}$ or $\mathrm{S} \neq \mathrm{SD}$, although the latter decision is frequently made by default with missing ancestors. The loss of SD also means loss of SSD, SSSD, SDSD, and all female ancestors as well. Such loss would impact efforts to estimate inbreeding in $\mathrm{X}$ or to declare $\mathrm{X}$ noninbred. Table 1 shows 15 possible positions where $\mathrm{S}$ might appear on the maternal side of the pedigree of $\mathrm{X}$ as well as the possible contribution to inbreeding if $\mathrm{S}$ was the same as the animal in each of those positions. The total possible contribution of all such common ancestor locations is 2.0. If some of those maternal ancestors were missing, the sum would be reduced. The infor- 


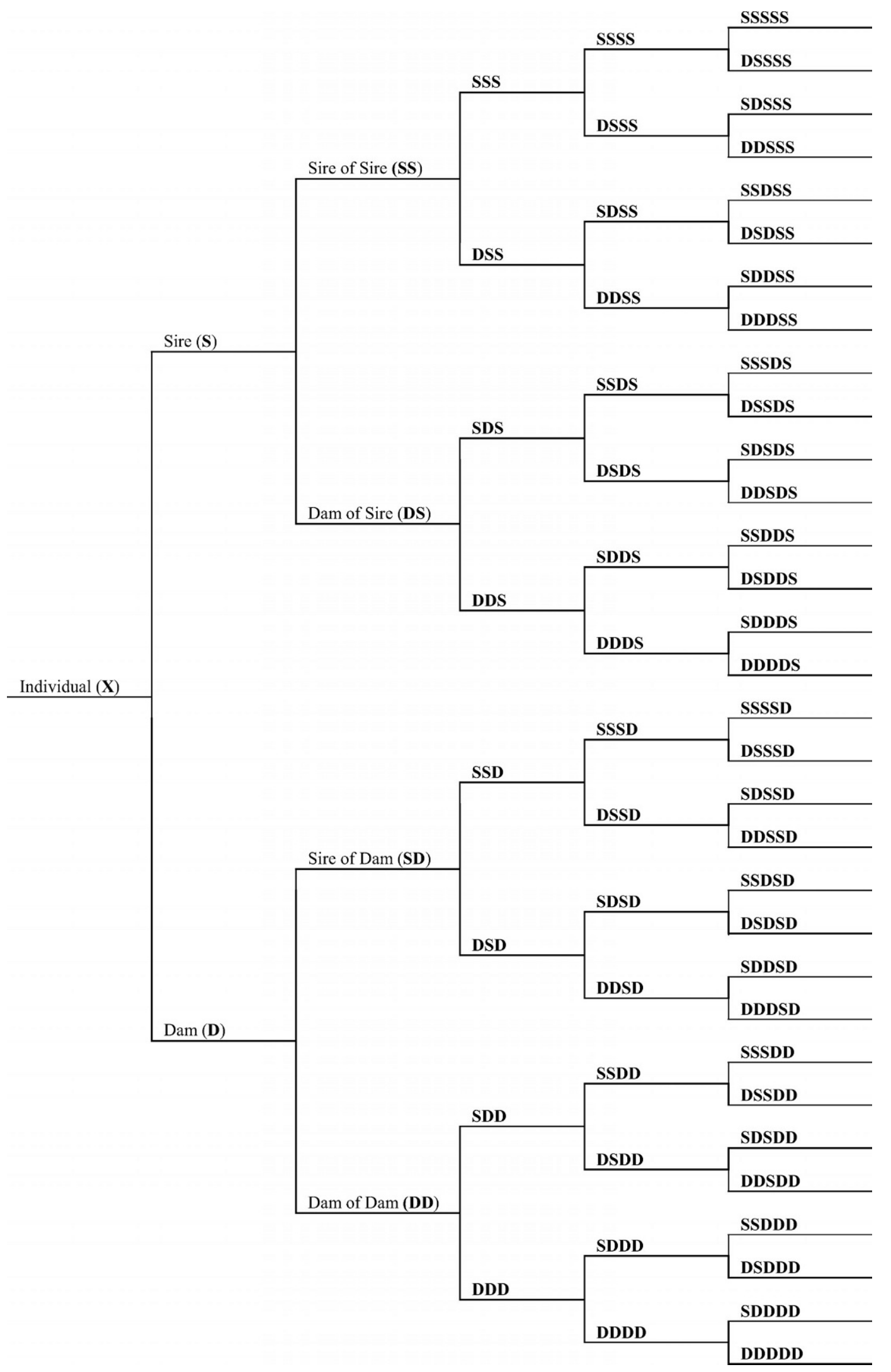

Figure 1. Abbreviations used for ancestors in a five-generation pedigree. 
Table 2. Potential contributions from ancestors on the paternal side of a five-generation pedigree to the numerator of the inbreeding coefficient when all ancestors are known on the maternal side.

\begin{tabular}{lll}
\hline & $\begin{array}{l}\text { Number of } \\
\text { similar } \\
\text { ancestors in a } \\
\text { five-generation } \\
\text { pedigree }\end{array}$ & $\begin{array}{l}\text { Maximum } \\
\text { possible } \\
\text { contribution } \\
\text { from each } \\
\text { ancestor }\end{array}$ \\
Ancestors & 1 & 2.0 \\
\hline S & 1 & 1.0 \\
SS & 1 & 1.5 \\
DS & 2 & 0.5 \\
SSS, SDS & 2 & 0.75 \\
DSS, DDS & 4 & 0.25 \\
SSSS, SDSS, SSDS, SDDS & 4 & 0.375 \\
DSSS, DDSS, DSDS, DDDS & 8 & 0.125 \\
DSSSS, DDSS, SSDSS, SDDSS, SSSDS, SDSDS, SSDDS, SDDDS & 0.1875 \\
Total of all contributions & 8 & 12.0 \\
\hline
\end{tabular}

mation lost by such missing ancestors could be estimated by ratio of the sum of contributions of males that remain to the maximum value of 2.0 if all male ancestors were present.

$\mathrm{S}$ is one of 16 male ancestors on the paternal side of the pedigree. Similar calculations can be made for the other ancestors. The total contribution of SS through all 15 possible locations on the maternal side of the pedigree would be 1.0, half that of $\mathrm{S}$, as an additional path of Mendelian segregation separates S and D through SS, rather than directly through S. The total contribution of DS is 1.5, half again the contribution of SS because DS could be D in a mother-son mating, whereas SS could only appear as a male ancestor to D. Table 2 shows the possible contribution of each paternal ancestor, male or female, to the numerator of equation 1 , assuming that the maternal side of the pedigree is complete for five generations. The sum of all possible paths through all possible ancestors of both sexes in any generation in a five-generation pedigree is 12.0. That total is useful as a standard for "complete" pedigree information, but could not occur in calculations of actual inbreeding coefficients. Animals cannot be their own parents. For this reason, our approach to evaluating completeness of pedigree information really measures the relative amount of information available to declare an animal non-inbred.

Table 3 shows the information loss associated with combinations of missing information on paternal and maternal sides of a pedigree. If the paternal side of the pedigree was complete for five generations (expected for a cow sired by an AI bull), but identification of DD was unknown, $39.6 \%$ of opportunity to declare an animal non-inbred would be lost through loss of SDD, DDD, SSDD, and so forth. If some paternal information, such as DDS were also missing, total loss of opportunity to declare an animal non-inbred would appear at the intersection of column DSS and row DD, $49.5 \%$ informa- tion loss. Such a pedigree could be considered to be (1 $-0.495) \times 100=50.5 \%$ complete.

This procedure is sensitive to the number of missing ancestors, their sex, and their location in a five-generation pedigree. The approach does not, however, consider the probability that a missing animal might actually be present on the other side of the pedigree. Maternal grand dams of grade cows will not likely appear in the pedigree of an AI bull. Females in the pedigrees of bulls in AI service have much higher probability of appearing on both sides of a pedigree. We developed a computer spreadsheet (available on request) to calculate information loss from any combination of missing information in a five-generation pedigree. The spreadsheet logic was converted to a SAS procedure that used a series of numerical binary variables to indicate presence of different ancestors on individuals in our data. These input streams were developed from pedigree data used by Animal Improvement Programs Laboratory (AIPL) to calculate inbreeding coefficients (Wiggans et al., 1995). We calculated the contribution from ancestor positions filled in pedigrees in our data and expressed that total as a percentage of the maximum value of 12.0 as our measure of pedigree completeness.

\section{The Data and Calculation of Inbreeding}

Data for this study were provided by Dairy Records Processing Center (DRMS), Raleigh, North Carolina, and consisted of first services to sires in AI performed on Holstein and Jersey cows with records processed at Raleigh in 1995 through 1998. Data were originally created for sire fertility evaluations calculated by DRMS Raleigh, and included herd, sire, cow identification, date of birth, date of calving, interval to first breeding, date and result of insemination, service sire identification, and summit milk yield (SM). Editing procedures eliminated records for missing sire or dam 
identification, services to bulls not in AI, missing or invalid information on herd or parity, any evidence of crossbreeding of cow or fetus, and interval to first breeding less than 20 or greater than $220 \mathrm{~d}$. Approximately $40 \%$ of original data were removed by our edits, leaving $1,780,283$ first services on 1,213,475 Holstein cows and 115,344 first service records on 77,379 Jersey cows. Holstein data included 441,096 registered and 772,379 grade cows, while Jersey data included 62,491 registered and 10,289 grade cows.

Pedigree files maintained by the AIPL, ARS, USDA, Beltsville, Maryland, for USDA genetic evaluations of dairy cattle in the fall of 1999 provided pedigree data for all Holstein and Jersey cows involved in this study. The AIPL pedigree files were updated well after DRMS Raleigh files were created, ensuring that all cows in DRMS data passing edits for inclusion in genetic evaluations had pedigree data as complete as available information would allow. The AIPL uses the method of Wiggans et al. (1995) to calculate inbreeding coefficients with average relationships replacing missing ancestors. These inbreeding coefficients, hereafter called AIPL inbreeding, were retrieved along with pedigree data. We constructed five-generation pedigrees and used the procedures of Golden et al. (1995) in the Animal Breeders Tool Kit (ABTK) to calculate inbreeding coefficients without the use of average relationships for missing pedigree data. These estimates are hereafter called ABTK inbreeding. We also merged pedigree data on cows in the DRMS Raleigh data with the AIPL pedigree data of the service sire contained in each reproductive record to construct a pedigree of the fetus. We calculated ABTK inbreeding of the fetus, but AIPL estimates of inbreeding in the fetus were not available.

Pedigree files were used to determine the percentage of pedigree completeness using the procedure described earlier. Following these calculations, Holstein-grade herds were divided into three categories based on completeness of pedigree. Group 1 included those herds in which more than $85 \%$ of cows had $30 \%$ or less ancestor information for estimating inbreeding in their pedigrees. Herds in group 2 included $85 \%$ or more cows with 31 to $70 \%$ pedigree completeness. Group 3 herds had the most complete pedigrees, with $85 \%$ or more cows with 71 to $100 \%$ of pedigree information available. Thus, some cows in each herd could have had pedigrees more or less complete than the standard met by $85 \%$ of cows in the herd. Registered Holstein herds were in a separate group because most registered cows had complete data. Jersey herds, which included some grade Jerseys, were not subdivided because only small numbers of Jersey cows had substantial missing pedigree data. The base for pedigree data from AIPL was 1960. Most cows in this study had birth dates in the early to mid 1990s, allowing opportunity for full five-generation pedigrees if the necessary ancestor identifications were reported through DHI over the years.

\section{Estimation of Inbreeding Depression}

Multiple records were available on individual cows and a repeatability mixed model was used to estimate the effects of inbreeding on days to first service (DTS) and SM. Summit milk was defined as the average of the two highest test-day milk weights out of the first three test days recorded for each cow. Effects of inbreeding on DTS and SM were estimated using MTDFREML (Boldman et al., 1995) and the following mixed model in matrix form:

$$
\mathrm{Y}=\mathrm{Xb}+\mathrm{Zu}+\mathrm{Wp}+\mathrm{e}
$$

where $\mathrm{Y}$ is a vector of observations, $\mathrm{X}, \mathrm{Z}$, and $\mathrm{W}$ are incidence matrices associating vectors of fixed effects and covariates (b), additive genetic effects ( $u$ ), and permanent environmental effects ( $p$ ) with the observations, and e is a vector of residual errors. The model is further specified as an animal model for repeated records on single traits.

Table 3. Percentage of information to declare an individual non-inbred that is missing from loss of individual ancestors or pairs of ancestors in five-generation pedigrees.

\begin{tabular}{|c|c|c|c|c|c|c|c|c|c|}
\hline \multirow{2}{*}{$\begin{array}{l}\text { Maternal } \\
\text { ancestor } \\
\text { missing }\end{array}$} & \multicolumn{9}{|c|}{ Paternal ancestor missing } \\
\hline & SS & DS & SSS & DDS & SSSS & DDDS & SSSSS & DDDDS & None \\
\hline DD & -63.5 & -65.6 & -48.4 & -49.5 & -42.4 & -43.0 & -40.2 & -40.5 & -39.6 \\
\hline SD & -65.6 & -71.9 & -51.6 & -54.7 & -46.1 & -47.7 & -44.1 & -44.9 & -43.8 \\
\hline DSD & -48.4 & -51.6 & -27.1 & -28.6 & -18.6 & -19.4 & -15.5 & -15.9 & -14.6 \\
\hline SSD & -49.5 & -54.7 & -28.6 & -31.3 & -20.4 & -21.7 & -17.4 & -18.1 & -16.7 \\
\hline DSSD & -42.4 & -46.1 & -18.6 & -20.4 & -9.2 & -10.1 & -5.7 & -6.2 & -4.7 \\
\hline SSSD & -43.0 & -47.7 & -19.4 & -21.7 & -10.1 & -11.3 & -6.7 & -7.3 & -5.7 \\
\hline DSSSD & -40.2 & -44.1 & -15.5 & -17.4 & -5.7 & -6.7 & -2.1 & -2.6 & -1.0 \\
\hline SSSSD & -40.5 & -44.9 & -15.9 & -18.1 & -6.2 & -7.3 & -2.6 & -3.1 & -1.6 \\
\hline None & -39.6 & -43.8 & -14.6 & -16.7 & -4.7 & -5.7 & -1.0 & -1.6 & 0.0 \\
\hline
\end{tabular}




$$
Y_{i j k l}=H Y S_{i}+P_{j}+\beta\left(F_{k}\right)+A_{k}+P E_{k}+E_{i j k l}
$$

In this representation, $\mathrm{Y}_{\mathrm{ijk}}$ is DTS or SM from the lth record of the kth cow in her jth parity calving in the ith herd-year season, HYS $_{\mathrm{i}}$ is the random effect of herd-year-season of calving, $P_{j}$ is the fixed effect of the jth parity ( 1 through 4$), \mathrm{F}_{\mathrm{k}}$ is inbreeding estimated by the AIPL or ABTK methods for cow $\mathrm{k}, \beta$ is the regression of DTS or SM on inbreeding, $A_{k}$ are the random, additive effect of genes of cow $\mathrm{k}, \mathrm{PE}_{\mathrm{k}}$ are random permanent environmental effects of cow $\mathrm{k}$, and $\mathrm{E}_{\mathrm{ijkl}}$ is random residual error associated with record $l$ on cow $\mathrm{k}$. Three generations of pedigree data were included in the relationship matrix for all analyses. Data files were too large to include all animals in the analyses. We created subsets for registered Holstein, grade Holstein, and Jersey cows by randomly selecting complete herds with at least five observations per herd-year-season, subject to the restriction that resulting datasets include between 70,000 and 80,000 records (approximately 50,000 cows).

\section{RESULTS AND DISCUSSION}

Table 4 shows the amount of pedigree information present for registered Holstein, grade Holstein, and Jersey cows. Pedigrees were most complete (97.7\%) in registered Holsteins, where over $83 \%$ of cows had all ancestors identified in their five-generation pedigrees. Almost no registered Holsteins had less than $70 \%$ of pedigree data available. Pedigree information on Jerseys was nearly as complete. More than $80 \%$ of these Jerseys were registered, and the grade Jerseys were apparently in herds where pedigree data were valued and maintained carefully. Pedigrees on grade Holsteins averaged slightly less than $50 \%$ complete. Two thirds of male and female ancestors were present in the average grade Holstein pedigree, but the location and combination of missing ancestors reduced the information available to declare these cows non-inbred by more than $50 \%$. For grade Holsteins, the ABTK estimate of inbreeding (where missing ancestors were ignored), was less than half the estimate the AIPL method, where average relationships were assumed for missing ancestors. However, when pedigree data were complete, or nearly so as in registered Holsteins, the two methods produced very similar average estimates of inbreeding, 3.64\% for ABTK and $3.50 \%$ for AIPL. If pedigree files were identical for AIPL and ABTK methods, average inbreeding should be very close for the two methods for cows with complete pedigrees. The method we used to construct pedigree files for the ABTK method included some ancestors born prior to 1960 , causing slightly higher inbreeding for registered Holsteins by the ATBK method. We did not observe the same effect in Jerseys, where AIPL inbreeding was $4.16 \%$ compared with $4.10 \%$ for ABTK. Jersey pedigrees were slightly less complete than registered Holstein pedigrees, perhaps allowing the missing information feature of the AIPL method to overshadow any additional pedigree data available to the ABTK method.

Table 5 includes the same cows as Table 4, grouped by percentage of pedigree information available. When the percentage of pedigree information available was less than $30 \%$, the ABTK method detected almost no inbreeding, regardless of breed or registry status. Inbreeding coefficients by the AIPL method averaged $3.55 \%$ for Jerseys, $2.67 \%$ for registered and $2.75 \%$ for grade Holsteins for cows with least pedigree information available. At the other extreme, $87 \%$ of Jersey cows had over $70 \%$ of pedigree data available, and averaged 4.27 and $4.56 \%$ percent inbreeding by the AIPL and ABTK methods. Estimates of inbreeding in the most complete pedigree group for Holsteins were higher for registered cows (3.71 and $3.53 \%$ for AIPL and ABTK methods, respectively) than for grade Holsteins (2.89 and 2.06 for AIPL and ABTK methods, respectively). The AIPL and ABTK inbreeding coefficients for grade Holsteins with more than $70 \%$ pedigree information present were more different than for registered Holsteins and Jerseys with the most complete pedigrees.

Table 4. Percentage of pedigree information available, proportion of male and female ancestors available, ${ }^{1}$ and estimated inbreeding coefficients calculated by two methods for registered and grade Holsteins and Jersey cows.

\begin{tabular}{|c|c|c|c|c|c|c|}
\hline \multirow[b]{2}{*}{ Variable } & \multicolumn{2}{|c|}{ 441,096 registered Holsteins } & \multicolumn{2}{|c|}{ 772,379 grade Holsteins } & \multicolumn{2}{|c|}{ 72,780 Jerseys } \\
\hline & Mean & SD & Mean & SD & Mean & $\mathrm{SD}$ \\
\hline Percentage of pedigree present & 97.7 & 10.2 & 49.2 & 34.5 & 89.6 & 25.0 \\
\hline Percentage of male ancestors present & 98.1 & 6.7 & 66.4 & 22.9 & 92.8 & 15.5 \\
\hline ABTK inbreeding $^{2}$ & 3.64 & 2.37 & 1.11 & 1.93 & 4.10 & 3.07 \\
\hline AIPL inbreeding ${ }^{3}$ & 3.50 & 2.35 & 2.92 & 1.90 & 4.16 & 2.81 \\
\hline
\end{tabular}

\footnotetext{
${ }^{1}$ Edits removed records where sire or dam identification was invalid or missing. Percent missing ancestors of either sex applies to grandparent or earlier generations.

${ }^{2}$ Estimates from the Animal Breeders Tool Kit using only information available in each pedigree.

${ }^{3}$ Estimates using average relationships for missing ancestors by the Animal Improvements Program Laboratory method of Wiggans (1995).
} 
Table 5. Effect of percentage of pedigree information available on inbreeding estimated by the classical pedigree approach (Animal Breeders Toolkit, ABTK) and a method of average relationships for missing ancestors (Animal Improvement Programs Laboratory, AIPL).

\begin{tabular}{|c|c|c|c|c|c|c|c|c|c|c|}
\hline \multirow[b]{3}{*}{ Breed } & \multicolumn{10}{|c|}{ Category of pedigree information available } \\
\hline & \multirow[b]{2}{*}{ Method } & \multicolumn{3}{|c|}{0 to $30 \%$} & \multicolumn{3}{|c|}{31 to $70 \%$} & \multicolumn{3}{|c|}{71 to $100 \%$} \\
\hline & & $\mathrm{n}$ & Mean & $\mathrm{SD}$ & $\mathrm{n}$ & Mean & $\mathrm{SD}$ & $\mathrm{n}$ & Mean & SD \\
\hline \multirow[t]{2}{*}{ Jersey } & AIPL & 5606 & 3.55 & 0.96 & 3832 & 3.46 & 2.71 & 63,342 & 4.27 & 2.91 \\
\hline & ABTK & $(7.7 \%)^{1}$ & 0.001 & 0.06 & $(5.2 \%)$ & 2.52 & 2.65 & $(87.0 \%)$ & 4.56 & 2.95 \\
\hline Registered & AIPL & 5198 & 2.67 & 0.70 & 5654 & 2.65 & 2.01 & 430,244 & 3.71 & 3.36 \\
\hline Holsteins & ABTK & $(1.2 \%)$ & 0.01 & 0.37 & $(1.3 \%)$ & 1.97 & 1.91 & $(97.5 \%)$ & 3.53 & 3.36 \\
\hline Grade & AIPL & 291,574 & 2.75 & 1.06 & 337,965 & 3.10 & 2.21 & 142,840 & 2.89 & 2.37 \\
\hline Holsteins & ABTK & $(37.8 \%)$ & 0.04 & 0.84 & $(43.8 \%)$ & 1.65 & 2.05 & $(18.5 \%)$ & 2.06 & 2.22 \\
\hline
\end{tabular}

${ }^{1}$ Numbers in parenthesis are the percentage of cows in the breed group with the amount of pedigree information indicated.

About half of the grade Holsteins in the group with most complete pedigrees had complete five-generation pedigrees, but about $25 \%$ had 90 to $99 \%$ percent of pedigree information present, and another $25 \%$ had 80 to $89 \%$ of pedigree information present. Very few of the grade cows in the most complete pedigree group had 70 to $79 \%$ of pedigree information present.

Percentage of pedigree information available on grade cows was not uniformly distributed from 0 to $100 \%$. Certain missing ancestors or combinations of ancestors that occurred frequently would produce such a result. For example, about $35 \%$ of all grade Holstein cows had between 60 and $69 \%$ of pedigree information available. If the dam of the dam of an individual were missing in an otherwise complete pedigree, the loss would eliminate $39.6 \%$ of information available to detect inbreeding (Table 3 ), leaving a pedigree $60.4 \%$ complete. Maternal ancestry is not required of records used in genetic evaluations in the United States, so such an omission could be common in AIPL pedigree files. Loss of this specific ancestor may not conceal much inbreeding, as these females are unlikely to appear on the paternal side of a pedigree created by use of registered bulls in AI. Male ancestors of those missing cows, however, would also be missing and might conceal some inbreeding.

We used DTS and SM to compare estimates of inbreeding depression across breeds and percentages of pedigree information available. Table 6 shows that DTS was longest for registered Holsteins (93.4 d) and shortest for Jerseys ( $84.4 \mathrm{~d}$ ). Differences in interval to first breeding for registered and grade Holsteins may reflect management strategies, such as use of more expensive semen in registered cows and an intentional delay before first service for a positive energy balance or strong estrus display before breeding. Means in Table 6 are not adjusted for herd effects. Removal of cows with extremely long intervals to first breeding did reduce means and standard deviations of DTS. Inbreeding depression was estimated from data with extreme DTS removed.

Table 7 shows summary statistics and inbreeding depression for DTS and SM for the samples of data created for analysis in grade Holsteins. Three datasets of approximately 50,000 cows each were created. At least $85 \%$ of cows in a herd were required to have the pedigree completeness percentage indicated for a herd to be assigned to a group. All cows and records from that herd were included, rather than just those cows with the indicated pedigree completeness. Our intent was to maintain the integrity of each herd. For the least complete group, only $5.6 \%$ of cows had inbreeding estimates above 0.0 for the ABTK method, but $99.9 \%$ of these same cows had inbreeding estimates above 0.0 by the AIPL method. In the most complete pedigree group, the AIPL method actually produced a lower percentage of cows with 0.0 inbreeding (98.0 vs. $99.9 \%$ ), because there were sufficient pedigree data to declare

Table 6. Days to first service in registered and grade Holstein and Jersey cows.

\begin{tabular}{|c|c|c|c|c|c|c|}
\hline \multirow[b]{2}{*}{ Breed } & \multicolumn{3}{|c|}{ Unrestricted } & \multicolumn{3}{|c|}{ Extreme intervals removed ${ }^{1}$} \\
\hline & $\mathrm{n}$ & Mean & SD & $\mathrm{n}$ & Mean & $\mathrm{SD}$ \\
\hline Jersey & 115,344 & 84.4 & 37.5 & 113,570 & 81.9 & 31.0 \\
\hline Registered Holsteins & 649,498 & 93.4 & 42.3 & 634,085 & 89.6 & 34.1 \\
\hline Grade Holsteins & $1,130,785$ & 89.2 & 41.0 & $1,107,499$ & 85.9 & 33.5 \\
\hline
\end{tabular}

${ }^{1}$ Maximum interval to first service was $200 \mathrm{~d}$ for Jerseys, $210 \mathrm{~d}$ for registered Holsteins, and $220 \mathrm{~d}$ for grade Holsteins. Minimum interval to first breeding was $20 \mathrm{~d}$ for all breeds. 
Table 7. Effects of inbreeding estimated by two methods on days to first service and summit milk yield in grade Holsteins with different amounts of pedigree data present.

\begin{tabular}{|c|c|c|c|c|c|c|}
\hline & \multicolumn{6}{|c|}{$\%$ Pedigree present } \\
\hline & \multicolumn{3}{|c|}{ ABTK method } & \multicolumn{3}{|c|}{ AIPL method } \\
\hline & 0-30\% & $30-70 \%$ & $70-100 \%$ & $0-30 \%$ & $30-70 \%$ & $70-100 \%$ \\
\hline Number of cows ${ }^{1}$ & 53871 & 48727 & 50734 & & & \\
\hline Number of records & 72398 & 72149 & 74822 & & & \\
\hline Percent cows with $\mathrm{F}(\mathrm{x})>0.0$ & 5.6 & 88.6 & 95.0 & 99.9 & 99.7 & 98.0 \\
\hline Average $\mathrm{F}(\mathrm{x})(\%)$ & 0.02 & 1.76 & 1.93 & 2.98 & 3.23 & 2.63 \\
\hline Standard deviation $\mathrm{F}(\mathrm{x})$ & 0.67 & 1.95 & 2.17 & 0.84 & 2.12 & 2.32 \\
\hline \multicolumn{7}{|l|}{ Days to first service $^{2}$} \\
\hline Mean (days) & 83.6 & 86.7 & 85.6 & & & \\
\hline Standard deviation & 33.3 & 32.4 & 31.7 & & & \\
\hline Inbreeding depression $/ 1 \% \mathrm{~F}(\mathrm{x})$ & -0.23 & 0.07 & 0.15 & -0.37 & 0.05 & 0.15 \\
\hline Standard error & 0.18 & 0.06 & 0.06 & 0.16 & 0.06 & 0.05 \\
\hline$P$-value & 0.208 & 0.276 & 0.006 & 0.023 & 0.358 & 0.004 \\
\hline Heritability & 0.03 & 0.04 & 0.07 & 0.03 & 0.04 & 0.07 \\
\hline \multicolumn{7}{|l|}{ Summit milk yield } \\
\hline Mean $(\mathrm{kg})$ & 36.1 & 37.9 & 38.0 & & & \\
\hline Standard deviation & 8.6 & 8.4 & 8.8 & & & \\
\hline Inbreeding depression $/ 1 \% \mathrm{~F}(\mathrm{x})$ & -0.12 & -0.06 & -0.06 & -0.07 & -0.07 & -0.06 \\
\hline Standard error & 0.04 & 0.01 & 0.01 & 0.03 & 0.01 & 0.01 \\
\hline$P$-value & $<0.001$ & $<0.001$ & $<0.001$ & 0.044 & $<0.001$ & $<0.001$ \\
\hline Heritability & 0.07 & 0.08 & 0.08 & 0.07 & 0.08 & 0.08 \\
\hline
\end{tabular}

some animals non-inbred. Average and standard deviation of inbreeding by the ABTK method increased with more complete pedigrees. Inbreeding estimated by the AIPL method changed slightly (not consistently increasing) with more pedigree information, but standard deviation of inbreeding increased considerably from least to most complete pedigrees. Days to first service was longest for the groups with the most complete pedigree data. Summit milk yield increased as the amount of pedigree data increased, perhaps reflecting better management conditions in herds with more complete pedigree data.

Heritability of DTS increased from 0.03 to 0.07 as completeness of pedigree information increased. The relationship matrix used for these analysis included up to three generations of ancestors, if available. It is possible that additional pedigree information in the most complete pedigree group enabled detection of additional additive genetic variation for DTS. However, heritability of summit milk yield was similar for all three groups at 0.07 to 0.08 . The method used to estimate inbreeding of the cow had no effect on estimates of heritability for either trait. Components of variance attributable to additive genetic effects were relatively small for both DTS and SM. We did not estimate nonadditive genetic effects directly, but inbreeding depression depends on nonadditive gene action. Hoeschele (1991) reported small inbreeding depression for days open $(+0.13 \mathrm{~d} / 1 \%$ increase in inbreeding) and for service pe- riod (days from first to last breeding) of $+0.10 \mathrm{~d} / 1 \%$ increase in inbreeding. Effects of inbreeding on total lactation yield were $-37 \mathrm{~kg} / 1 \%$ increase in inbreeding in registered Holsteins, but only $-16 \mathrm{~kg} / 1 \%$ inbreeding in grade Holsteins in Smith et al. (1998). Thompson et al. (2000) did report undesirable but small and variable effects of inbreeding on test-day milk yield. Traits other than DTS or SM such as standardized lactation milk yield might have been more useful to demonstrate the effects of incomplete pedigrees on estimates of inbreeding depression.

Estimates of inbreeding depression in grade Holsteins was nonsignificant for the two groups of herds with least pedigree information available for both AIPL and ABTK methods of estimating inbreeding. Inbreeding depression in DTS was significant and unfavorable $(P<0.01)$ in herds where over $85 \%$ of cows had at least $70 \%$ of pedigree information present in five-generation pedigrees. Inbreeding depression for SM was significant $(P<0.01)$ for all three groups of herds, and by either method in estimating inbreeding except for the 0 to $30 \%$ pedigree group with AIPL inbreeding. All estimates of inbreeding depression were unfavorable, but less damaging when more pedigree data were available. For SM, use of inbreeding coefficients from animals with limited pedigree data would have lead to an overestimate of the negative effects of inbreeding in these data samples. For DTS, limited pedigree data likely would have pro- 
Table 8. Effects of inbreeding estimated by two methods on days to first service and summit milk yield in Jerseys and registered Holstein cows with different amounts of pedigree data present. ${ }^{1}$

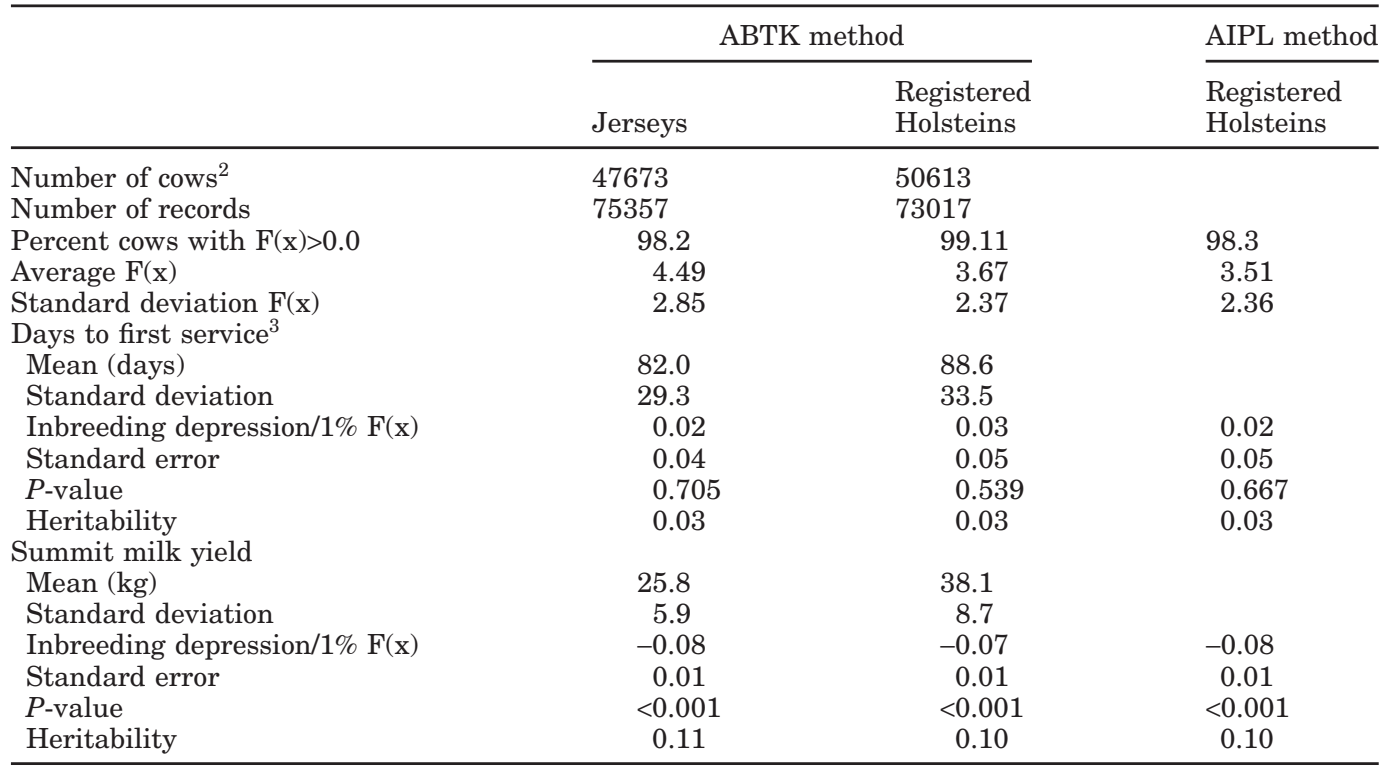

${ }^{1} \mathrm{ABTK}=$ Animal Breeders Toolkit, AIPL = Animal Improvement Programs Laboratory.

${ }^{2}$ Data within each percentage of pedigree present are identical for ABTK and AIPL methods.

${ }^{3}$ Extreme intervals removed $(20 \leq \mathrm{X} \leq 220)$.

duced nonsignificant inbreeding effects if data from all three groups of herds had been pooled.

Table 8 shows the same results as Table 7 , but for registered Holstein and Jersey cows. We did not examine inbreeding depression using AIPL estimates of inbreeding for Jerseys. Means for DTS were higher for registered Holsteins (88.6 d) than for Jersey (82.0) or for grade Holsteins (83.6 to $86.7 \mathrm{~d}$, Table 7) and were more variable. Mean SM was similar for the group of grade Holsteins with most complete pedigree data and registered Holsteins. Heritabilities for DTS were 0.03 for both registered Holsteins and Jerseys, a slightly lower estimate than for two of the three grade Holstein groups in Table 7. However, heritability for SM was higher in both registered Holsteins and Jerseys $(0.10$ or 0.11 ) than for grade Holsteins (0.07 to 0.08). Accuracy of pedigree information may contribute to the difference for SM, but heritabilities for DTS do not support that conclusion.

Inbreeding depression for DTS was not significant $(P$ $<0.01$ ) for either breed in Table 8. The (nonsignificant) estimate of inbreeding depression for registered Holsteins was very similar (0.03- or 0.02-d increase in DTS per $1 \%$ increase in inbreeding) for ABTK and AIPL estimates of inbreeding. Average inbreeding was similar for the two methods (3.67\% for ABTK and 3.51 for AIPL) as would be expected for registered cows with very complete pedigree information. Inbreeding depression for SM was highly significant $(P<0.01)$ for both
Jerseys and registered Holsteins and was similar $(-0.07$ to $-0.08 \mathrm{~kg}$ per $1 \%$ increase in inbreeding) for both breeds. The estimate of inbreeding depression in grade Holsteins with most complete pedigrees was $-0.06 \mathrm{~kg}$ per $1 \%$ increase in inbreeding.

One interesting comparison in these results is between the group of grade Holsteins with most complete pedigree data and registered Holsteins or Jerseys. Heritability of DTS for the grade cows was 0.07 , and inbreeding depression for DTS was significant $(P<0.01)$ with 0.15 -d increase in DTS per $1 \%$ increase in inbreeding. Heritability for the same trait in registered Holsteins was less than half as large, 0.03 , while inbreeding depression of 0.02 or $0.03 \mathrm{~d}$ increase per $1 \%$ increase in inbreeding was not significant. Jersey results for DTS were similar to registered Holsteins. These results could be attributable to the sample of data analyzed or to differences in how the trait is expressed in registered and grade Holsteins. Days to first service is a management decision, affected by biological processes. It is possible that the role of biology in expression of DTS is greater in grade Holsteins, or these grade Holsteins at least, than in these registered Holsteins. Both the grade and registered Holsteins produced the same significant inbreeding depression for SM, $-0.06 \mathrm{~kg}$ per $1 \%$ increase in inbreeding. We conclude that inbreeding depression can be estimated accurately from grade data, but pedigrees must be nearly complete for several generations. There is evidence to suggest that for some traits such 
as DTS, groups of cows can be managed for different purposes, and genetic components affecting the resulting phenotypes may be affected.

\section{CONCLUSIONS}

Inbreeding does not have a large or consistently significant effect on DTS in either Jerseys or grade and registered Holstein cows. The small effect that does exist is unfavorable. Inbreeding depression does reduce $\mathrm{SM}$, just as it has been shown to reduce annual milk and component yield in many studies. The amount of pedigree information from which inbreeding is estimated affects the estimates of inbreeding depression. Partial pedigrees reduce the average inbreeding estimate and the variance of such estimates in groups of cows. Attempting to regress a response variable on estimates of inbreeding from partial pedigrees will not necessarily produce the same estimate of inbreeding depression obtained from complete pedigrees. It is rational to expect that more complete pedigree information will produce more accurate estimates of inbreeding depression, though many other factors-accuracy of pedigree and phenotypes, size of datasets, statistical procedures, and models used-will impact such a conclusion.

We present a method of measuring the completeness of pedigree data and demonstrate its utility for editing data before estimating the effects of inbreeding. Our method could be coupled with current algorithms for estimating inbreeding with little additional computational investment. Replacement of missing ancestors with average relationships for animals born in the same year, currently used by AIPL, cannot replace missing information in a manner useful for estimating inbreeding depression. Statistical properties of the AIPL inbreeding coefficients depend on the proportion of pedigree information available. Unusual behavior of regression coefficients can be expected, especially in pedigrees with large amounts of missing information. The AIPL method has merit for other applications, but not for estimation of inbreeding depression. Grade cows with relatively complete pedigree data are useful for estimating inbreeding depression, but should not be used for that purpose unless the pedigrees are complete.

\section{ACKNOWLEDGMENTS}

We wish to thank Holstein Association, USA, and the American Jersey Cattle Association for financial support, DRMS Raleigh for phenotypic information, and AIPL, USDA, for pedigree data and inbreeding coefficients used in this study.

\section{REFERENCES}

Boldman, K. G., L. A. Kriese, L. D. Van Vleck, C. P. Van Tassell, and S. D. Kachman. 1995. A manual for use of MTDFREML. A set of programs to obtain estimates of variances and covariances. [Draft], USDA-ARS, Lincoln, NE.

Golden, B. L., W. M. Snelling, and C. H. Mallinckrodt. 1995. Animal Breeder's Tool Kit 2.0. User's Guide and Reference Manual. Department of Animal Sciences, Colorado State University, Ft. Collins.

Hoeschele, I. 1991. Additive and nonadditive genetic variance in female fertility of Holsteins. J. Dairy Sci. 74:1743-1752.

Lutaaya, E., I. Misztal, J. K. Bertrand, and J. W. Mabry. 1999. Inbreeding in populations with incomplete pedigrees. J. Anim. Breed. Genet. 116:475-480.

Miglior, F., and E. B. Burnside. 1995. Inbreeding of Canadian Holstein cattle. J. Dairy Sci. 78:1163-1167.

Miglior, F., E. B. Burnside, and B. W. Kennedy. 1995. Production traits of Holstein cattle: estimation of nonadditive genetic variance components and inbreeding depression. J. Dairy Sci. 78:1174-1180.

Smith, L. A., B. G. Cassell, and R. E. Pearson. 1998. The effects of inbreeding on the lifetime performance of dairy cattle. J. Dairy Sci. 81:2729-2737.

Thompson, J. R., R. W. Everett, and N. L. Hammerschmidt. 2000. Effects of inbreeding on production and survival in Holsteins. J. Dairy Sci. 83:1856-1864.

VanRaden, P. M. 1992. Accounting for inbreeding and crossbreeding in genetic evaluation of large populations. J. Dairy Sci. 75:3136-3144.

Wiggans, G. R., P. M. Van Raden, and J. Zuurbier. 1995. Calculation and use of inbreeding coefficients for genetic evaluation of United States dairy cattle. J. Dairy Sci. 78:1584-1590. 